\title{
Awareness and utilization of dental services among secondary school student in Moshi municipality
}

\author{
Mhagama $\mathbf{M}^{\mathbf{1}}$, Mwangosi IEAT ${ }^{2}$ \\ ${ }^{1}$ Mawenzi Referral Regional Hospital, Moshi Municipality, Tanzania \\ ${ }^{2}$ Muhimbili School of Assistant Dental Officers, Tanzania
}

Mhagama M, Mwangosi IEAT

Awareness and utilization of dental services among secondary school students in Moshi municipality.

Tanz Dent J 2010, 16 (2):44-47

\begin{abstract}
Aim: To determine the awareness and utilization of dental services among secondary school students in Moshi Municipality. Materials and Methodology: This cross sectional study among 200 secondary school students aged 13-21 years old was done using a supervised Kiswahili self administered questionnaire. Two schools were conveniently chosen to obtain the needed sample of participants into this study. The data were analyzed using the SPSS version 13.0. The significance level was set at $\mathrm{p}<0.05$. Results: About $55 \%$ of the participants were aware of the dental services rendered. Proportionately more males were aware of dental services (63.6\%), and utilized the services (48.6\%) than females (44.1\% and $44.1 \%$ respectively). Older students were more aware of the dental services (56.6\%) and less utilized them (41.0\%) compared to younger students (52.6\% and 55.1\% respectively). Students who had moderate to high level of awareness utilized dental services more (59.1\%) than those with low levels of awareness (40.8\%). Conclusion: More than half of the respondents were aware of the available dental services. Only 46.5\% had utilized dental services during their lifetime. Students with moderate to high levels of awareness utilized dental services more than those with low levels of awareness.
\end{abstract}

Correspondence: Dr. Ibrahim EAT Mwangosi, Muhimbili School of Assistant Dental Officers, P.O. Box 65594, Dar es Salaam, Tanzania, Tel (mobile): 0713-705869, E-mail: ieatmwangosi@yahoo.com

\section{Introduction}

Oral Health is an integral to general health and essential for well being. Good oral heath means being free from periodontal diseases, caries and other diseases and disorders that affect the oral cavity. Most people tend to neglect the fact that dental health should be incorporated into general health (l).

Dental diseases are generally not self-limiting. If untreated, dental conditions may affect the person's well being and overall quality of life. Without knowledge and understanding of available dental services there can be no informed decision for promotion of oral health (2). Giving priority to prevention is often undermined by most individuals; most dental services provided are curative, rehabilitative and emergency care (3). Many people do not have a regular routine of attending dental clinics for check up but visits are based on dental pain and treatment given is usually extraction $(4,5)$.

Lack of knowledge and awareness of need for treatment is the major reason which hinders utilization of health facilities and patients delay to seek treatment (6). Increase in knowledge on oral health lead to an increase in awareness and finally increase in utilization of the dental services (7). With proper knowledge during adolescence, this can maintain good quality of life in adulthood $(8,9,10$, 11).

Various studies on oral health knowledge and the levels of utilization of dental services have been done in Tanzania $(8,12,13)$, but no published reports from Moshi Municipality were retrieved. Therefore, the objective of this study was to determine the awareness and utilization of dental services among students in Moshi Municipality.

\section{Methodology}

A cross-sectional study was designed to recruit 200 students from two conveniently selected co-education secondary schools in Moshi Municipality. Systematic random sampling technique was used to get participants from school registers. A hundred students from each of the two selected schools were systematically sampled to participate in the study.

A structured questionnaire was prepared in English and later translated into Kiswahili and pre-tested before the actual study. The sociodemographic variables included age, gender, name of school and residence. The questionnaire enquired on the reasons and recommended frequency of visits to an oral health facility, awareness on various types of oral 
health care services and the sources of this information.

Data collection was done using a self-administered questionnaire. Students filled the questionnaire in class rooms in the presence of the researcher. Data were entered into the computer and analysed using SPSS version 13.0. Awareness was computed by summation of positive responses to questions on types of dental services rendered. A score of $50 \%$ to $100 \%$ was categorised as moderate to high awareness, and $0 \%-49 \%$ as low. A participant who had attended to an oral health facility at least once during her/his lifetime was regarded as having utilized an oral health service. Frequency distributions and cross-tabulations were done and chi square test was used to test for significant associations. The significance level was set at $\mathrm{p}<0.05$.

\section{Results}

The frequency distribution of the participants by their socio-dermographic characteristics is shown in Table 1. The participants' age ranged from 13-21 years, males were $53.5 \%$ and $83 \%$ of the participants were from urban areas.
Table 1: Distribution of participants by sociodemographic characteristics $(\mathrm{N}=\mathbf{2 0 0})$

\begin{tabular}{lcc}
\hline $\begin{array}{c}\text { Demographic } \\
\text { characteristics }\end{array}$ & No & \% \\
\hline Age-group & & \\
$13-16$ & 78 & 39 \\
$17-21$ & 122 & 61 \\
Sex & & \\
$\quad$ Males & 107 & 53.5 \\
$\quad$ Females & 93 & 46.5 \\
Name of School & & \\
$\quad \begin{array}{l}\text { Mawenzi } \\
\text { Majengo }\end{array}$ & 100 & 50 \\
Residence & 100 & 50 \\
$\quad$ Rural & & \\
$\quad$ Urban & 34 & 17 \\
\hline
\end{tabular}

Table 2 shows that a slightly higher proportion (56.6\%) of the participants aged 17-21 years had moderate to high level of awareness of dental services rendered at dental clinics than 13-16 years old students (52.6\%). Males were significantly more aware of dental services (63.6\%) than females $(44.1 \%)\left(\chi^{2}=7.6, \mathrm{p}<0.01\right)$.

Participant's level of utilizing available dental services is shown in Table 3 . Only $46.5 \%$ of the participants had utilized dental services in their lifetime. Proportionately more participants in the age group 13-16 years had utilized dental service than those aged $17-21$ years $\left(\chi^{2}=3.82, \mathrm{p}<0.05\right)$. There were no statistically significant differences in the utilization of dental services between sexes or level of awareness.

Table 2: Distribution of participants by level of awareness, age and sex

\begin{tabular}{lcccccccccccc}
\hline & \multicolumn{4}{c}{ Age-group (yrs) } & \multicolumn{4}{c}{ Sex* } & \multicolumn{3}{c}{ Total } \\
\hline Level of awareness & \multicolumn{2}{c}{$13-16$} & \multicolumn{1}{c}{$17-21$} & \multicolumn{2}{c}{ Total } & \multicolumn{2}{c}{ Males } & \multicolumn{2}{c}{ Females } \\
& $\mathrm{N}$ & $\%$ & $\mathrm{~N}$ & $\%$ & $\mathrm{~N}$ & $\%$ & $\mathrm{~N}$ & $\%$ & $\mathrm{~N}$ & $(\%)$ & $\mathrm{N}$ & $(\%)$ \\
\hline Moderate to High & 41 & 52.6 & 68 & 55.7 & 109 & 54.5 & 68 & 63.6 & 41 & 44.1 & 109 & 54.5 \\
Low & 37 & 47.4 & 54 & 44.3 & 91 & 45.5 & 39 & 36.4 & 52 & 55.9 & 91 & 45.5 \\
Total & 78 & 39.0 & 122 & 61 & 200 & 100 & 107 & 53.5 & 93 & 46.5 & 200 & 100 \\
\hline
\end{tabular}

$* \chi^{2}=7.6 ; \mathrm{p}<0.01$

\section{Discussion}

In the current study, the level of awareness on dental services rendered at dental clinics did not vary significantly with age. This indicates that awareness does not rise as one move from age-group or school year to the other. However, male students were significantly more aware of dental services than female students. This indicates that male students are more exposed to sources of information such as TV, radio and newspapers than female students.
The fact that $46.5 \%$ of the participants had utilized dental services in their lifetime indicates that a big proportion of Tanzanians have dental problems since majority of Tanzanians visit dental clinics for emergency care when they are in pain. Proportionately more participants from the younger age group had utilized dental service than the older age group. This may reflect improvements in oral health services overtime, thus provided an 
opportunity for care. Dental caries in Tanzania affects the primary dentition more than the secondary dentition (14, 15), thus probably, as services improved; the older age group had passed the primary dentition age. The findings from this study show the participants aged 13-16 years utilized more dental services (55.1\%) compared to $17-21$ age group (41\%). These findings are similar to a study by Dasayanake et al (1) where $30 \%$ of the younger age group (below 16 years) utilized more dental services.

Table 3:Distribution of participants by level of utilization of dental services by age, sex and level of awareness

\begin{tabular}{|c|c|c|c|c|c|c|c|c|c|c|c|c|c|c|c|c|c|c|}
\hline \multirow{3}{*}{ Utilization } & \multicolumn{6}{|c|}{ Age Group in years* } & \multicolumn{6}{|c|}{ Sex } & \multicolumn{6}{|c|}{ Level of awareness** } \\
\hline & \multicolumn{2}{|c|}{$13-16$} & \multicolumn{2}{|c|}{$17-21$} & \multicolumn{2}{|c|}{ Total } & \multicolumn{2}{|c|}{ Males } & \multicolumn{2}{|c|}{ Females } & \multicolumn{2}{|c|}{ Total } & \multicolumn{2}{|c|}{ Low } & \multicolumn{2}{|c|}{$\begin{array}{c}\text { Moderate } \\
\text { to high }\end{array}$} & \multicolumn{2}{|c|}{ Total } \\
\hline & $\mathrm{n}$ & $\%$ & $\mathbf{n}$ & $\%$ & $\mathrm{n}$ & $\%$ & $\mathrm{n}$ & $\%$ & $\mathbf{n}$ & $\%$ & $\mathbf{n}$ & $\%$ & $\mathbf{n}$ & $\%$ & $\mathrm{n}$ & $\%$ & $\mathbf{n}$ & $\%$ \\
\hline Utilized & 43 & 55.1 & 50 & 41 & 93 & 46.5 & 52 & 48.6 & 41 & 44.1 & 93 & 46.5 & 38 & 41.8 & 55 & 50.4 & 93 & 46.5 \\
\hline $\begin{array}{l}\text { Not } \\
\text { Utilized }\end{array}$ & 35 & 44.9 & 72 & 59 & 107 & 53.5 & 55 & 51.4 & 52 & 55.9 & 107 & 53.5 & 53 & 58.2 & 54 & 49.6 & 107 & 53.5 \\
\hline Total & 78 & 39 & 122 & 61 & 200 & 100 & 107 & 53.5 & 93 & 46.5 & 200 & 100 & 91 & 45.5 & 109 & 54.5 & 200 & 100 \\
\hline
\end{tabular}

$* \chi^{2}=3.82, \mathrm{p}<0.05 ; * * \chi^{2}=1.5, \mathrm{p}>0.05$.

There being no statistically significant differences in the utilization of dental services between sexes indicate that there is equal access to service for both sexes. The findings differ from the study by Dasayanake et al (1) in which, females utilized more the available services (51.2\%) and a study by Mosha (6) which reported that more females (52.1\%) were users of dental care services than males (43\%).

Lack of statistically significant differences in the utilization of dental services between level of awareness, indicate that level of awareness is not necessarily directly related to utilization of services.

Results from this study show that the utilization of dental health services is not directly related to the levels of awareness of the available dental services unlike in a study by Mumghamba et al (2) where it was shown that one's knowledge of oral health would lead to an informed decision on utilization.

\section{Conclusion and Recommendations}

More than half of the respondents were aware of the available dental services. Only $46.5 \%$ had utilized dental services during their lifetime. Students with moderate to high levels of awareness utilized dental services more than those with low levels of awareness. Nevertheless, more studies need to be done to verify any relationship between awareness of available dental services and utilization of the services.

\section{Acknowledgement}

The authors thank the Moshi Municipality authorities for granting permission to carry out the study. We also thank the Kilimanjaro Regional Medical Officer (RMO) and the Ministry of Health and Social Welfare (Training Directorate) for the financial support.

\section{Referrences}

1. Dasanayake, A.P. Li, Y. Wadhawan et al., (2002). Disparities in dental service utilization among Alabama Medicaid children. Community Dent Oral Epidemiol, 30:369-376.

2. Mumghamba E.G.S. (2005). Awareness on cause, risk factors and prevention of periodontal diseases among secondary school students in Kinondoni District. Dar-es-Salaam, Tanzania. Tan Dent J. Nov; 12(1):1-2.

3. Abrahamson, J.H. and Abrahamson Z.H. (1999). Survey methods in community medicine, Epidermiological research programme, evaluation and clinical trials, Church Livingstone $5^{\text {th }}$ edition.

4. Adegbembo, A.O. (1994). Household utilization of dental services in Ibadan, Nigeria. Community Dent Oral Epidemiol; 22:338-339.

5. Varenne, B., Petersen, E., and Ouattara, S. (2006). Oral health behaviour of children and adults in urban and rural areas of Burkina Faso, Africa. Int Dent J; 56:61-70.

6. Mosha H.J. and Scheutz, F. (1993). Perceived need and use of oral health services amongadolescents and adults in Tanzania. Community Dent Oral Epidemiol; 21:129-132.

7. Honkala,E. Kuusela, S. Rimpelä, B., Rimplelä M., and Jokela, J. (1997). Dental services utilization between 1977 and 1995 by Finnish adolescents of different socioeconomic levels. Community Dent Oral Epidemiol, 25:385-390

8. Ntabaye M.K. Scheutz, F. and Poulsen, S. (1998). Patient satisfaction with emergency oral health care in rural Tanzania. Community Dentistry and Oral Epidemiology; 26:289 -295 
9. Okullo I. Åstrøm, A.N. and Haugejorden, O. (2004). Social inequalities in oral health and in use of oral health care services among adolescents in Uganda. Int $J$ Paediatr Dent 14:326-335

10. Westaway, M.S, Viljoen, E. and Rudolph, M.J. (1999). Utilisation of oral health services, oral health needs and oral health status in a periurban informal settlement. SADJ, 54:149-152

11. Yu, S.M. Bellamy, H.A. Schwalberg et al., (2001). Factors associated with use of preventive dental and health services among U.S. adolescents. J Adolesc Health. 29:395-405.

12. Åstrøm, A.N, Jackson W., Mwangosi I.E. (2000). Knowledge, beliefs and behavior related to oral health among Tanzanian and Ugandan teacher trainees. Acta Odontol Scand. 58:11-8
13. Matee M., Simon E. (2000). Utilization of dental services in Tanzania before and after the introduction of cost-sharing. Int Dent J. 50:69-72

14. Petersen PE, Nyandindi U, Kikwilu EN, Poulsen VJ. Oral health status and oral health behaviour of school children, teachers and adults in Tanzania. WHO technical report 2002.

15. Mosha HJ, Ngilisho WAF, Mkwera H, Scheutz F, Poulsen S. Oral health status and treatment needs in different age groups in two regions of Tanzania. Community Dent Oral Epidemiol 1994; 22:307-10. 